\title{
Hippocampal Cell Responses in Mice with a Targeted Glucocorticoid Receptor Gene Disruption
}

\author{
Wouter Hesen, ${ }^{1}$ Henk Karst, ${ }^{1,2}$ Onno Meijer, ${ }^{2}$ Tim J. Cole, ${ }^{3}$ Wolfgang Schmid,, ${ }^{3}$ E. Ronald de Kloet, ${ }^{2}$ \\ Gunther Schütz, ${ }^{3}$ and Marian Joëls ${ }^{1}$ \\ ${ }^{1}$ Department of Experimental Zoology, University of Amsterdam, 1098 SM Amsterdam, The Netherlands, ${ }^{2}$ Division of \\ Medical Pharmacology, Leiden Amsterdam Center for Drug Research, Leiden University, 2300 RA Leiden, The \\ Netherlands, and ${ }^{3}$ German Cancer Research Institute, DE-69009 Heidelberg, Germany
}

Previous studies in rats have shown that cellular properties of hippocampal CA1 neurons are under coordinative control of mineralocorticoid and glucocorticoid receptors (MRs and GRs, respectively). In the present study, we examined electrical properties under conditions of exclusive MR occupation, by using mice with a genetic defect in GRs obtained by homologous recombination techniques. It appeared that in the animals homozygous for the genetic defect, the properties studied, i.e., the voltage-gated $\mathrm{Ca}$ currents and responses to serotonin and the cholinergic analog carbachol, resembled the effects observed in adrenalectomized mice, i.e., when no steroid receptors are activated. This may point to the necessity of functional GRs for the development of
MR-induced actions. Ca current amplitude and transmitter responses in the heterozygous animals, which combine a reduced amount of GRs in the hippocampus with relatively high circulating levels of corticosterone, were large compared with those in the wild-type controls; this resembles the responses that were observed previously in rats subjected to a very high dose of corticosterone. These findings exemplify the use of GR knockout mice for the study of cellular properties in the brain. Further substantiation of the observations, however, awaits the development of site-specific, inducible GR knockouts.

Key words: calcium currents; serotonin; carbachol; hexokinase; electrophysiology; quantitative enzyme histochemistry
The adrenal hormone corticosterone passes the blood-brain barrier and binds to two types of intracellular receptors in the brain: the mineralocorticoid receptor $(\mathrm{MR})$, with a high $\left(K_{\mathrm{d}}=0.5 \mathrm{nM}\right)$ affinity for corticosterone, and the glucocorticoid receptor (GR), with a 10-fold lower affinity (Hollenberg et al., 1985; Reul and de Kloet, 1985; McEwen et al., 1986; Arriza et al., 1987; de Kloet, 1991). The hippocampus is one of the main targets for corticosteroid hormones in the brain (Fuxe et al., 1985; Reul and de Kloet, 1985; McEwen et al., 1968; van Eekelen et al., 1987, 1988; Chao et al., 1989; Herman et al., 1989). Because of circadian and poststress variations in plasma corticosterone level, MR and GR occupation will vary throughout the day (Reul et al., 1987a,b). When corticosterone levels are low, MRs are already considerably activated, but GR activation is limited. When corticosterone levels rise, GRs are activated in addition to MRs.

Previous electrophysiological studies showed that corticosteroid hormones, via MR and GR, exert a delayed and persistent control over intrinsic membrane properties and neurotransmitter responses of CA1 hippocampal neurons (Joëls and de Kloet, 1994). Predominant MR activation in tissue from adrenalectomized $(\mathrm{ADX})$ rats is associated with small Ca currents through voltagegated $\mathrm{Ca}$ channels, a stable response to synaptic input mediated by excitatory and inhibitory amino acids, and small responses to

\footnotetext{
Received June 5, 1996; revised July 26, 1996; accepted Aug. 20, 1996.

H.K. was supported by Grant A110 of the Dutch Epilepsy Foundation. This work was supported by European Commission Biotechnology Programme PL960179. The work of Dr. W. van Raamsdonk and M. Smit-Onel on the determination of hexokinase activity is gratefully acknowledged.

Correspondence should be addressed to M. Joëls, Department of Experimental Zoology, University of Amsterdam, Kruislaan 320, 1098 SM Amsterdam, The Netherlands.

Copyright (C) 1996 Society for Neuroscience $0270-6474 / 96 / 166766-09 \$ 05.00 / 0$
}

serotonin [5-hydroxytryptamine (5HT)] and the metabolically stable cholinergic agent carbachol (CCh) (Joëls et al., 1991; Kerr et al., 1992; Hesen and Joëls, 1993; Joëls and de Kloet, 1993; Karst et al., 1994). Additional GR activation in ADX animals results in an increased $\mathrm{Ca}$ influx, decrease of synaptic response to amino acids, and relatively large effects by $5 \mathrm{HT}$ and $\mathrm{CCh}$. Comparable responses were observed in cells from adrenally intact rats with moderately high corticosterone levels. In the absence of steroids, i.e., in untreated ADX rats, Ca currents were enhanced compared with those in adrenally intact rats (Karst et al., 1994), whereas responses to $5 \mathrm{HT}$, and to a lesser extent $\mathrm{CCh}$, were comparable to the situation in adrenally intact rats (Joëls and de Kloet, 1992; Hesen and Joëls, 1993).

The specific receptor occupation in these studies was achieved by using selective MR and GR agonists or MR and GR antagonists. Thus, MR occupation was induced by applying low doses of corticosterone or aldosterone, or by administering higher corticosterone doses in the presence of the GR antagonist RU486. Because of the fact that the agonists used are not fully selective (for review, see de Kloet, 1991) and the antagonists act in a competitive manner (Gagne et al., 1985), MR occupation could not be achieved in the absence of some GR activation, albeit to a limited extent.

Recently, animals with a disruption in the GR gene were obtained by the use of homologous recombination in mouse embryonic stem cells (Cole et al., 1995). Animals homozygous for the disruption offer the possibility of studying corticosteroidinduced regulation of excitability in the hippocampal CA1 area in the complete absence of functional GRs. If the small Ca currents and small transmitter responses observed previously with predominant MR activation are caused exclusively by activation of MRs, 
we hypothesize that similar small cellular responses will be observed in the homozygous GR mutant mice. If interaction between MRs and (a limited amount of) GRs is required to evoke functional actions of steroids (Arriza et al., 1988; Trapp et al., 1994; Trapp and Holsboer, 1996), however, we expect that MRmediated events will not take place in the homozygous mutants, resulting in a situation resembling that of ADX animals.

In the present study, we compared the following parameters in animals that were homozygous or heterozygous for the GR gene defect and in wild-type controls: (1) plasma corticosterone levels and expression of hippocampal MR and GR mRNA, to get an impression of neuroendocrine regulation; 2) voltage-gated $\mathrm{Ca}$ currents of CA1 pyramidal neurons, which is the intrinsic membrane property that is most clearly affected by steroid treatment; (3) responses to 5HT and $\mathrm{CCh}$, which in the rat were found to be very sensitive to steroid receptor occupation; and (4) the activity of hexokinase, which catalyzes the phosphorylation of glucose, the first rate-limiting step in cellular glucose metabolism; this can serve as an index for the metabolic state of hippocampal subfields in the three animal groups.

\section{MATERIALS AND METHODS}

Animals. The mouse GR gene was disrupted in embryonic stem cells using a replacement vector strategy, as described earlier (Cole et al., 1995). Positive clones were used for injection into C57BL/6 blastocysts to generate chimeric mice. Chimeras were mated with both C57BL/6 and $129 / \mathrm{J}$ animals to generate an outbred and isogenic colony. Fifty percent of the offspring were heterozygous for the GR-mutated allele. Mice homozygous for the GR mutation were generated by intercrossing of heterozygous mice. Of all the mice included in the present study, genotypes were determined by Southern blotting of tail DNAs. Wild-type controls were obtained from the offspring of intercrossed heterozygous mice $(n=$ 4) or from the F1 generation of C57BL/6 (females) crossed with Ola 129 (males; $n=6$ ). The latter two groups were randomly tested during the series of experiments. No significant differences were observed, with respect to the tested parameters, between the two control groups. Therefore, the data were pooled.

Wild-type $(n=10)$, heterozygous $(n=9)$, and homozygous $(n=8)$ mice (all males) were transported from Heidelberg to Amsterdam at least 4-6 weeks before the experiment. They were housed individually in an animal house with alternating light/dark cycle (lights on at 7.00 A.M.). Adrenalectomy (5-7 d) was performed as described elsewhere (Ratka et al., 1989). The animals received food and water (saline after adrenalectomy) ad libitum. The age of the animals ranged from 4 to 10 months. Two series of experiments were performed. In the first series, animals were subjected to behavioral tests, starting $\sim 2$ weeks after the animals arrived and ending 2-3 weeks before the start of the electrophysiological experiments. The delay between behavioral and electrophysiological tests was kept constant for all animals. In the second series, animals were not subjected to behavioral tests and were used for experiments $\sim 4$ weeks after arrival. No qualitative differences were observed for the cellular properties between these two experimental series, indicating that the effect of previous exposure to behavioral tests did not interfere with the present results.

Preparation of the tissue. On the day of the experiment ( 9:30 A.M.), the mice were exposed to a novel environment for 30-60 min before decapitation. Plasma corticosterone levels were determined with a radioimmunoassay in trunk blood obtained during decapitation; levels in wild-type mice showed that animals were mildly stressed. Exposure to a novel environment was introduced for three reasons. First, by subjecting animals to a novelty stress, a mildly elevated plasma corticosterone level was evoked in all mice. Individual differences between animals and uncontrollable shifts in circulating corticosteroid levels before decapitation were thus masked. Second, elevated plasma corticosterone levels are likely to activate most of the available GRs. Differences in the availability of functional GRs between the experimental groups are likely to be most apparent under these conditions. Finally, a similar experimental procedure was used in earlier studies in rats (Joëls and de Kloet, 1992; Hesen and Joëls, 1993, 1996a,b; Karst et al., 1994). By keeping experimental conditions similar, the results from the present and earlier studies can be carefully compared.
One hemisphere was deep-frozen on dry ice or in liquid nitrogen and stored for later analysis with quantitative enzyme histochemistry or in situ hybridization. The other hemisphere was cut into transversal hippocampal slices $(300 \mu \mathrm{m})$ on a McIlwain tissue chopper. Slices were stored at room temperature in carbogenated $\left(95 \% \mathrm{O}_{2} / 5 \% \mathrm{CO}_{2}\right)$ artificial cerebrospinal fluid (ACSF) of the following composition (in mM): $120 \mathrm{NaCl}, 3.5$ $\mathrm{KCl}, 1.3 \mathrm{MgSO}_{4}, 1.25 \mathrm{NaH}_{2} \mathrm{PO}_{4}, 2.5 \mathrm{CaCl}_{2}, 10$ D-glucose, and 25 $\mathrm{NaHCO}_{3}$. One slice at a time was submerged in a recording chamber and perfused continuously $(2 \mathrm{ml} / \mathrm{min})$ with warm $\left(32^{\circ} \mathrm{C}\right)$ carbogenated ACSF.

In situ hybridization. Sections $(10 \mu \mathrm{m})$ were cut on a cryostat, thawmounted on poly-L-lysine-coated slides, and kept at $-80^{\circ} \mathrm{C}$ until further use. In situ hybridization was performed using ${ }^{35} \mathrm{~S}$-labeled riboprobes. For the GR, a $0.52 \mathrm{~kb}$ SalI-HindII fragment of exon 2 of the mouse GR gene in pBluescript was used; for the MR, a $5.0 \mathrm{~kb}$ EcoRI fragment of exon 2 of the mouse MR gene in pBluescript was used. Antisense and sense probes were generated from linearized plasmids using either T3 or T7 RNA polymerase. The MR probe was hydrolyzed by incubation in $90 \mathrm{~mm}$ $\mathrm{Na}_{2} \mathrm{CO}_{3} / 60 \mathrm{~mm} \mathrm{NaHCO}$ at $60^{\circ} \mathrm{C}$ for 20 min to get smaller fragments and thus allow for a single hybridization protocol.

Before hybridization, the sections were fixed in $4 \%$ paraformaldehyde in PBS, $\mathrm{pH} \mathrm{7.2,} \mathrm{for} 60 \mathrm{~min}$ at room temperature, rinsed twice in PBS, permeabilized by proteinase $\mathrm{K}$ treatment, rinsed briefly in DEPC-treated water, acetylated with $0.25 \%$ acetic anhydride in $0.1 \mathrm{M}$ triethanolamine, rinsed for $10 \mathrm{~min}$ in $2 \times \mathrm{SSC}$, and dehydrated in a graded ethanol series. A hybridization mix containing $70 \%$ formamide, $10 \%$ dextran sulfate, $3 \times$ SSC, $0.06 \mathrm{M}$ sodium phosphate buffer, $1 \times$ Denhardt's solution, $10 \mathrm{~mm}$ dithiothreitol, $0.1 \mathrm{mg} / \mathrm{ml}$ yeast tRNA, and $0.1 \mathrm{mg} / \mathrm{ml}$ salmon sperm DNA was prepared. Riboprobes were added to this mix to a concentration of $40 \times 10^{6} \mathrm{dpm} / \mathrm{ml}$. One hundred microliters of this mix were applied to each slide, which was then covered with a standard microscopic coverslip and put in moist chamber for overnight hybridization at $53^{\circ} \mathrm{C}$. The next day, the coverslips were removed, and the slides were washed in $2 \times$ SSC, treated with RNase $\mathrm{A}$, and washed at $55^{\circ} \mathrm{C}$ in $2 \times \mathrm{SSC}, 1 \times \mathrm{SSC}$, and $0.1 \times$ SSC. The slides were dehydrated in a graded ethanol series, put in a cassette, and exposed to an X-OMAT AR film (Kodak, Rochester, NY) for $6-14 \mathrm{~d}$.

The autoradiograms were quantified using an Olympus image analysis system with the appropriate software. After shading correction, the hippocampal images were corrected for film background. Optical density of the CA1 area was measured with the use of standard curves (Amersham, Buckinghamshire, UK). Six to ten sections were analyzed per animal.

Quantitative enzyme histochemistry. Hexokinase antibodies were raised as described elsewhere (Van Raamsdonk et al., 1996). Cryostat sections $(10 \mu \mathrm{m})$ were cut at $-25^{\circ} \mathrm{C}$ and collected on glass slides coated with poly-L-lysine. The reaction was performed on fresh cryostat sections at $40^{\circ} \mathrm{C}$. The freshly prepared incubation medium had the following composition (in mM): 40 glucose, $12.5 \mathrm{ATP}, 1 \mathrm{NADP}^{+}, 20 \mathrm{MgCl}_{2}, 5 \mathrm{NaH}_{3}$, and 0.33 methoxyphenazine methosulfate (Serva, Heidelberg, Germany), in $100 \mathrm{~mm}$ HEPES-KOH buffer, $\mathrm{pH} 7.7,16 \%$ polyvinyl alcohol, and $5 \mathrm{~mm}$ tetranitro-blue tetrazolium (Sigma, St. Louis, MO) dissolved by gentle heating in a mixture of ethanol and dimethylformamide. The final concentration of dimethylformamide was $4 \%(\mathrm{v} / \mathrm{v})$ and of ethanol was $2 \%$ $(\mathrm{v} / \mathrm{v})$. Control sections were incubated in a medium without glucose and ATP. After incubation, the sections were post-fixed for $15 \mathrm{~min}$ at room temperature in $4 \%$ paraformaldehyde and $2 \% \mathrm{CaCl}_{2}$ and then washed in distilled water. The sections were embedded in glycerol gelatin.

Cytophotometry was performed with a computer program for image processing $\mu$ Image (developed by P. C. Diegenbach). The program was run on an Apple Macintosh IIcx connected with a frame grabber and a black/white CCD video camera with a $604 \times 576$ pixel array, on a Leitz microscope $(12.5 \times$ objective $)$ with a $546 \mathrm{~nm}$ interference filter. The collected data represented mean integrated absorbance values. Images were corrected for background absorbance by subtraction of a blank image that was taken near the object on the slide. The linearity of the assay was established extensively in tissue from the zebrafish (Van Raamsdonk et al., 1996). Studies in mouse hippocampal tissue exhibited comparable linearity over the range in which experimental values were measured (data not shown).

Ca currents. Hippocampal pyramidal CA1 neurons in slices were selected for recording with a light microscope (Nikon 104, 400×). The selected cell was approached with a patch pipette (Sutter micropipette puller; $1.5 \mathrm{~mm}$ outer diameter borosilicate glass; 1.5-3.0 M 2 ). Positive pressure ensured that the tip of the electrode was kept clean and that the surface of the membrane was freed from surrounding neuropil (based on 
Table 1. Comparison of cellular properties in adrenally intact wild-type (WT/I), heterozygous (HE/I), and homozygous (HO/I) GR knockouts and in adrenalectomized wild-type (WT/ADX) and heterozygous (HE/ADX) animals

\begin{tabular}{|c|c|c|c|c|c|}
\hline Parameters & $\begin{array}{l}\text { WT/I } \\
(10,7,7)\end{array}$ & $\begin{array}{l}\mathrm{HE} / \mathrm{I} \\
(11,9,7)\end{array}$ & $\begin{array}{l}\mathrm{HO} / \mathrm{I} \\
(9,8,6)\end{array}$ & $\begin{array}{l}\text { WT/ADX } \\
(4,4,4)\end{array}$ & $\begin{array}{l}\text { HE/ADX } \\
(4,5,5)\end{array}$ \\
\hline$[\mathrm{CORT}](\mu \mathrm{g} / \mathrm{dl})$ & $2.8 \pm 0.9$ & $5.8 \pm 1.5^{*}$ & $15.7 \pm 1.5^{*}$ & & \\
\hline MR mRNA & $359 \pm 24$ & $345 \pm 14$ & $301 \pm 19$ & & \\
\hline RMP (mV) & $-64 \pm 2$ & $-64 \pm 2$ & $-64 \pm 2$ & $-67 \pm 3$ & $-64 \pm 2$ \\
\hline$R_{\mathrm{in}, \mathrm{m}}(\mathrm{M} \Omega)$ & $56 \pm 5$ & $67 \pm 4$ & $59 \pm 7$ & $50 \pm 6$ & $59 \pm 3$ \\
\hline$R_{\mathrm{in}, \mathrm{p}}(\mathrm{M} \Omega)$ & $195 \pm 16$ & $189 \pm 15$ & $168 \pm 17$ & $186 \pm 17$ & $197 \pm 19$ \\
\hline$V_{\mathrm{H}}(\mathrm{mV})$ & $-92 \pm 2$ & $-90 \pm 1$ & $-94 \pm 2$ & $-89 \pm 1$ & $-87 \pm 3$ \\
\hline$V_{\mathrm{C}}$ & $11 \pm 1$ & $12 \pm 1$ & $11 \pm 1$ & $11 \pm 1$ & $13 \pm 1$ \\
\hline$t_{-20}(\mathrm{msec})$ & $59 \pm 3$ & $60 \pm 3$ & $59 \pm 2$ & $72 \pm 6^{*}$ & $75 \pm 5^{*}$ \\
\hline$t_{0}(\mathrm{msec})$ & $59 \pm 3$ & $57 \pm 3$ & $54 \pm 3$ & $58 \pm 4$ & $61 \pm 9$ \\
\hline
\end{tabular}

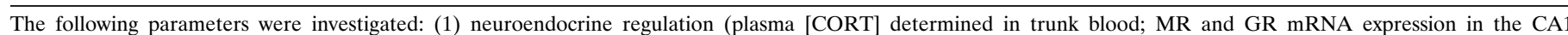

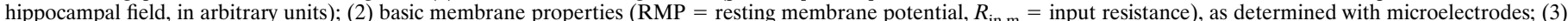

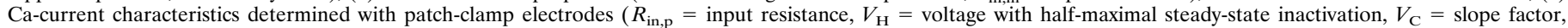

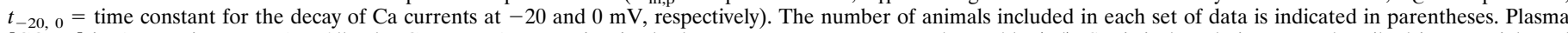

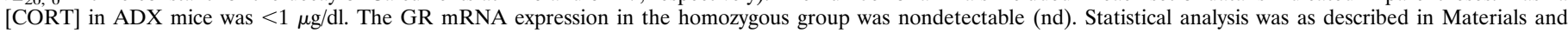
Methods (*p $<0.05)$

method of Edwards et al., 1989). When the tip of the electrode was placed on the membrane, a giga seal was established by application of light suction; additional suction resulted in the whole-cell recording configuration. For the recording of $\mathrm{Ca}$ currents, the pipette solution consisted of (in mM): $100 \mathrm{CsF}, 0.5 \mathrm{CaCl}_{2}, 2 \mathrm{MgCl}_{2}, 2 \mathrm{MgATP}, 0.1 \mathrm{NaGTP}, 10 \mathrm{HEPES}$, 10 EGTA, 20 creatine phosphate, $50 \mathrm{U} / \mathrm{ml}$ creatine phosphokinase, 0.1 albumin, and $20 \mathrm{TEACl}, \mathrm{pH} 7.4,300 \mathrm{mOsm}$. This solution was frozen and kept on ice during the day of the experiment. Furthermore, $0.5 \mu \mathrm{M}$ tetrodotoxin was added to the extracellular ACSF to block Na currents; $\mathrm{K}$ conductances were blocked by extracellular addition of $10 \mathrm{~mm}$ tetraethylammonium $\mathrm{HCl}, 5 \mathrm{~mm}$ 4-aminopyridine, and $5 \mathrm{~mm} \mathrm{CsCl}$. In a limited number of experiments ( $n=3$ animals for each group), sustained $\mathrm{Ca}$ currents were recorded with a pipette solution containing $100 \mathrm{~mm} \mathrm{Cs}$ methylsulfonate instead of $\mathrm{CsF}$, because the latter was reported to alter amplitude and kinetic properties, particularly of the sustained Ca currents (Kay et al., 1986). Although recording with Cs methylsulfonate indeed resulted in an increase (by $\sim 30-50 \%$ ) of the Ca current amplitude, qualitative differences were not seen. That is, cells from heterozygous animals still displayed on average the largest amplitude for sustained $\mathrm{Ca}$ current $\left(I_{\mathrm{Ca}, \mathrm{ni}}\right.$, see below). Because no qualitative differences were seen for the two pipette solutions, and many more observations were made with CsF, we will limit our present report to the latter.

Whole-cell currents were measured under voltage-clamp conditions using a Biological RK300 amplifier. Data were collected with an Atari computer, at $1 \mathrm{kHz}$ sampling rate (of the computer). Data acquisition and analysis were performed as described elsewhere (Karst et al., 1994; Joëls and Karst, 1995). All data about Ca current activation presented in this paper were collected at $10 \mathrm{~min}$ after the whole-cell configuration was established; inactivation properties were established after $15 \mathrm{~min}$. Single exponential functions were fitted to the inactivation phase of the transient inward Ca current. The same least-square minimization algorithm was used to estimate the Boltzmann curves for steady-state inactivation of the transient Ca currents. Routinely, correction for linear leak-current and capacity transients was applied as described in detail elsewhere (Joëls and Karst, 1995); current properties were not basically altered by these correction procedures. Series resistance was not compensated, justified by the combination of a low access resistance $(\sim 4 \mathrm{M} \Omega)$ and small current amplitudes (1-2 nA).

Transmitter responses. Intracellular recordings were obtained from CA1 pyramidal neurons with conventional methods, using glass microelectrodes filled with $4 \mathrm{M}$ KAc yielding impedances of 80-130 M $\Omega$. Voltage signals were passed to an NPI amplifier. The membrane potential and current injections were registered continuously on a chart recorder. Hyperpolarizing currents were passed through the microelectrode to determine input resistance, as described elsewhere (Hesen and Joëls, 1993; Joëls and de Kloet, 1993). Neurons included in this study displayed stable resting membrane potentials between -60 and $-70 \mathrm{mV}$, input resistances of at least $30 \mathrm{M} \Omega$, and spike amplitudes of at least $80 \mathrm{mV}$.
Drugs were applied to the slices via the perfusion medium. CCh (carbamyl-choline-chloride, Sigma) and serotonin (5HT creatine sulfate, Sigma) were dissolved as $1 \mathrm{~mm}$ stock in ACSF and stored at $-20^{\circ} \mathrm{C}$. Before application, the drugs were diluted to the final concentration (3 and $10 \mu \mathrm{M}$, respectively). Membrane potential and input resistance were recorded before, during, and after drug administration.

Data analysis. All data were collected and analyzed before the genotype of the animal was known. The identity of the genotype was revealed only at the final stage of data analysis. Statistical analysis of the differences between the three adrenally intact groups was performed by a one-way ANOVA, followed by a post hoc unpaired Student's $t$ test $(p<0.05)$. ADX wild-type and heterozygous mice were tested against the adrenally intact groups with an unpaired Student's $t$ test. When animals were grouped according to age, i.e., $<6$ months $(n=7), 6-9$ months $(n=7)$, or $>9$ months $(n=6)$, no significant differences were observed for any of the tested cellular properties.

\section{RESULTS}

As shown in Table 1, plasma corticosterone levels at the start of the experiment showed significant differences for the three experimental groups. In heterozygous mice, corticosterone levels were increased twofold, whereas in the homozygous mutants the increase was approximately fivefold.

The expression levels for the MR and GR mRNA in the CA1 area were also clearly different for the three experimental groups. Compared with the wild-type group, heterozygous animals displayed a significantly reduced level of GR mRNA, whereas MR mRNA levels were comparable. In tissue from the homozygous mutants, GR mRNA was undetectable. On average, the MR mRNA expression level was reduced, compared with that of the wild-type group, but this did not attain statistical significance.

\section{Ca currents}

Inward Ca currents were recorded from CA1 pyramidal neurons in hippocampal slices, with the patch-clamp technique in the whole-cell mode (Edwards et al., 1989). The Ca currents were evoked by brief $(200 \mathrm{msec})$ depolarizing steps to potentials varying from -100 to $0 \mathrm{mV}$, as described elsewhere (Karst et al., 1994; Joëls and Karst, 1995). Total Ca current was studied by applying a $3 \mathrm{sec}$ hyperpolarizing prepulse $(-130 \mathrm{mV})$ to remove steadystate inactivation (Fig. 1A). Appreciable currents were evoked by depolarizing steps to $-70 \mathrm{mV}$; maximal currents were observed 
A
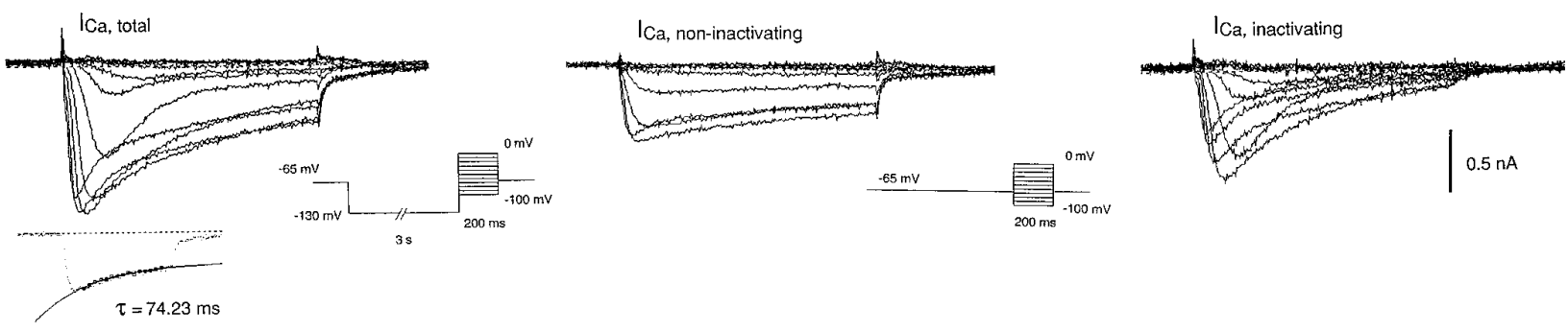

B
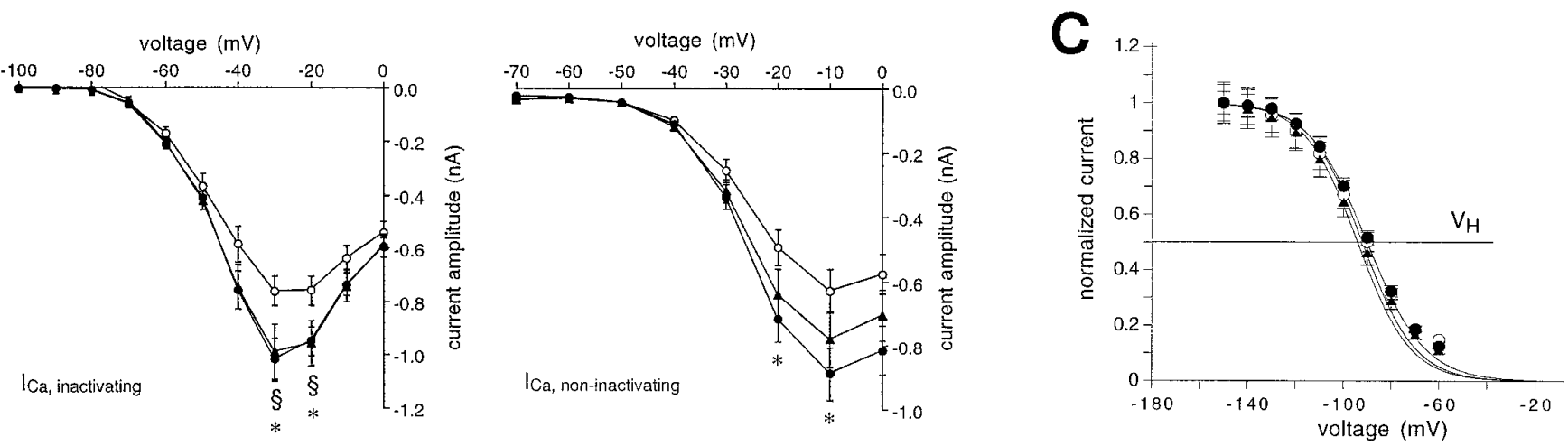

Figure 1. A, Typical Ca currents of a mouse CA1 pyramidal neuron recorded in a hippocampal slice with the patch-clamp technique, in the whole-cell mode. Left traces represent the total Ca current evoked with a voltage protocol as depicted in the inset. The middle traces show the Ca currents that are not subject to steady-state inactivation $\left(I_{\text {Ca,noninactivating }}\right)$, evoked by the indicated voltage protocol. The traces on the right were obtained by subtraction of the $I_{\mathrm{Ca}, \text { ni }}$ from the total Ca current, and they represent the transient Ca currents $\left(I_{C a, \text { inactivating }}\right)$. All traces shown were subjected to correction for leak currents and capacity transients. $B$, Current-voltage plots for the $I_{\text {Ca,inactivating }}$ and $I_{\text {Ca,noninactivating }}$ recorded in cells from wild-type $(O, n=24$ cells), heterozygous $(\bullet, n=26)$, and homozygous $(\boldsymbol{\Lambda}, n=24)$ GR knockout mice. Data represent mean \pm SEM. For each voltage step, these values were tested with a one-way ANOVA followed by a Student's $t$ test for multiple comparisons of the mean $\left({ }^{*}, \S p<0.05\right.$ for the heterozygous and homozygous groups, respectively, compared with wild types). Similar differences between groups were found when data were analyzed per animal instead of per cell. $C$, Voltage dependency of the steady-state inactivation. Data represent the mean normalized current recorded with a prepulse of the indicated voltage level, stepped to $-40 \mathrm{mV}$. For each group of animals, the normalized currents were fitted by a Boltzmann equation (drawn line). No differences were observed among the three experimental groups.

around $-10 \mathrm{mV}$. Currents not liable to steady-state inactivation $\left(I_{\mathrm{Ca}, \mathrm{ni}}\right)$ were studied by applying depolarizing voltage steps directly from the holding potential $\left(V_{\mathrm{hr}}=-65 \mathrm{mV}\right.$; Fig. $\left.1 \mathrm{~A}\right)$. These currents typically appeared by depolarizing steps to $-40 \mathrm{mV}$ and peaked around $-10 \mathrm{mV}$ (Fig. $1 B$ ). By subtracting the $I_{\mathrm{Ca}, \text { ni }}$ from the total Ca current, we could study the currents showing strong inactivation in isolation $\left(I_{\mathrm{Ca}, \mathrm{i}}\right.$; Fig. $\left.1 A\right)$. These transient currents became apparent with depolarization to $-70 \mathrm{mV}$ and reached maximal values at $-30 \mathrm{mV}$ (Fig. 1B).

Voltage properties of the Ca current activation were not different for the three experimental groups; however, the amplitude of the $I_{\mathrm{Ca}, \mathrm{ni}}$ and $I_{\mathrm{Ca}, \mathrm{i}}$ were significantly enhanced in neurons from heterozygous GR knockout animals (Fig. 1B). Currents in neurons from homozygous mutants were also increased compared with the wild-type controls. The latter attained statistical significance for the $I_{\mathrm{Ca}, \mathrm{i}}$ but not for the $I_{\mathrm{Ca}, \mathrm{ni}}$. Input resistances for the three groups were not different (Table 1).

Inactivation properties were studied by varying the voltage of the prepulse and subsequently applying a voltage step to $-40 \mathrm{mV}$. The currents were normalized to the maximal current and fitted with a Boltzmann equation $I(V) / I_{\max }=1 /\left[1+\exp \left\{\left(V-V_{\mathrm{H}}\right) / V_{\mathrm{C}}\right\}\right]$, where $I(V) / I_{\max }$ is the normalized current at membrane potential $V, V_{\mathrm{H}}$ is the voltage of half-maximal inactivation, and $V_{\mathrm{C}}$ is proportional to the slope factor of the curve (Fig. 1C). As indi- cated in Table 1 , neither $V_{\mathrm{H}}$ nor $V_{\mathrm{C}}$ displayed any difference between the experimental groups. We also studied the decay of the $\mathrm{Ca}$ current, which could be fitted with a single exponential function (inset in Fig. $1 A$ ). Also for this parameter, comparable values were observed for the three experimental groups (Table 1). Therefore, heterozygous animals and to a lesser degree homozygous mutant mice showed an increased amplitude of voltagegated $\mathrm{Ca}$ currents compared with the wild-type controls, without changes in voltage dependency or kinetic properties.

To compare Ca currents of the homozygous mutants, where exclusively MRs are activated, with animals where neither MRs nor GRs are activated, we adrenalectomized some of the heterozygous and wild-type mice. The limited amount of homozygous mutant mice did not permit investigation after they were adrenalectomized. In Figure 2, averaged peak currents are depicted for voltage steps to $-50,-30$, and $-10 \mathrm{mV}$. Values for the step to $-50 \mathrm{mV}$ are indicative for the transient, low-threshold (T-type) Ca current (Karst et al., 1993). The step to $-30 \mathrm{mV}$ illustrates the maximal $I_{\mathrm{Ca}, \mathrm{i}}$, whereas the currents evoked at $-10 \mathrm{mV}$ correspond to the maximal $I_{\mathrm{Ca}, \mathrm{ni}}$ (Karst et al., 1994). It appeared that in neurons from wild-type animals, the amplitude of the Ca current evoked by a step to $-30 \mathrm{mV}$ was enhanced $(0.3 \mathrm{nA})$ after adrenalectomy to a level that was observed in both the intact and ADX heterozygous animals (Fig. 2). No effects of adrenalectomy in 
Figure 2. Mean (+SEM) Ca current amplitudes evoked by a voltage step to $-50,-30$ (both $\left.I_{\mathrm{Ca}, \mathrm{i}}\right)$, and $-10 \mathrm{mV}\left(I_{\mathrm{Ca} \text {,ni }}\right)$ in neurons from adrenalectomized wild-type $(W T / A D X ; n=20$ cells) and heterozygous animals $(H E / A D X ; n=16)$, compared with the adrenally intact controls (WT/I and $H E / I$, respectively). In cells from wild-type animals, adrenalectomy increased the current induced by a depolarizing step to -30 $\mathrm{mV}$, to a level that is comparable to the current observed in ADX and adrenally intact heterozygous mice. In heterozygous ADX mice, only a small reduction of the current evoked by a depolarization to $-50 \mathrm{mV}$ was observed.

wild-type animals were observed for the other voltage steps tested. In neurons from the heterozygous mice, adrenalectomy induced a slight $(0.1 \mathrm{nA})$ but significant reduction of the $I_{\mathrm{Ca}, \mathrm{i}}$ at $-50 \mathrm{mV}$. Currents evoked by the other two voltage steps were not changed after adrenalectomy. In general, the currents observed in ADX wild-type and ADX heterozygous animals were similar to the currents observed in the adrenally intact heterozygous and homozygous mutants. As shown in Table 1, the time constant for the decay was increased after adrenalectomy for both groups, for a voltage step to $-20 \mathrm{mV}$ but not for a step to $0 \mathrm{mV}$ (Table 1).

\section{Serotonin and $\mathrm{CCh}$ responses}

Neurons recorded with a microelectrode displayed no differences with respect to membrane potential or input resistance among the three experimental groups (Table 1). This result agrees with the findings with patch-clamp electrodes.

Bath-applied 5HT induced a hyperpolarization of the membrane accompanied by a decrease in resistance (Fig. $3 A$ ), similar

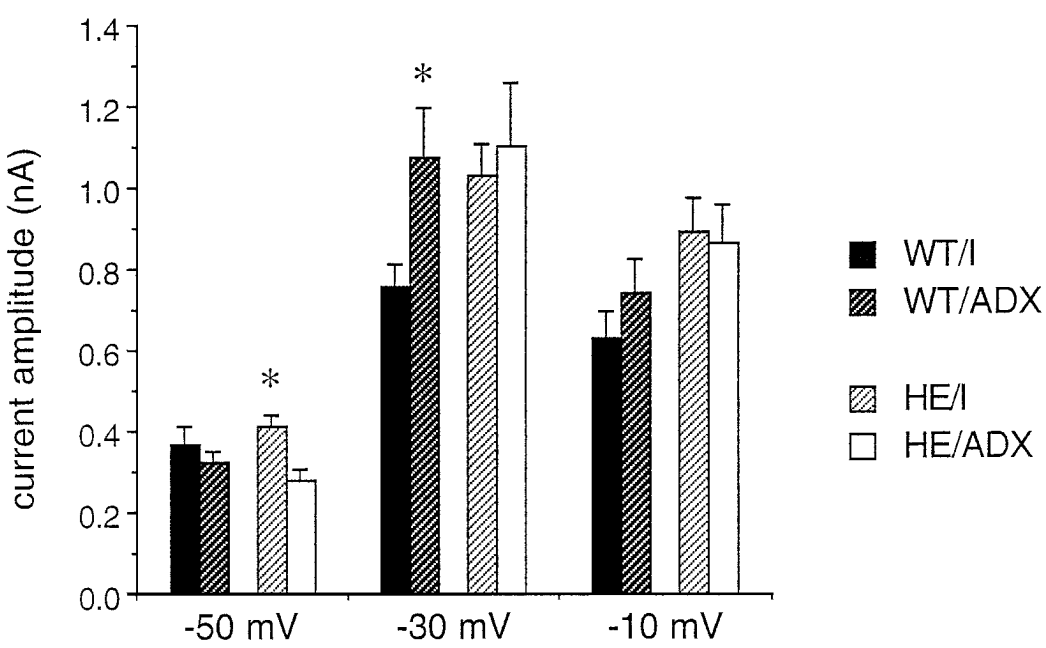

to what has been found previously in rats (Andrade and Nicoll, 1987). In a limited amount of cells $(n=3)$ from control mice, a dose-response curve was constructed. These curves showed that, as in rats, $10 \mu \mathrm{M}$ 5HT induced near-maximal effects on membrane potential. This dose was selected for subsequent experiments.

In the wild-type controls, $10 \mu \mathrm{M} 5 \mathrm{HT}$ hyperpolarized the membrane by $\sim 6 \mathrm{mV}$ (Fig. $3 B$ ). The $5 \mathrm{HT}$ effect on membrane potential was significantly $(p<0.05)$ enhanced in the group of heterozygous animals, whereas the 5HT response in the homozygous mutants was again comparable to that of the wild-type controls. These effects on membrane hyperpolarization were paralleled by the decrease of resistance. Neurons from heterozygous animals exhibited a significantly more reduced membrane resistance in the presence of 5HT than did the neurons from wild-type controls. The homozygous group displayed intermediate values. The increased responsiveness to $5 \mathrm{HT}$ was no longer observed when heterozygous animals were adrenalectomized. The membrane hyperpolarization in ADX het-
Figure 3. A, Typical hyperpolarization induced by superfused 5HT $(10 \mu \mathrm{M})$ in a CA1 pyramidal neuron of a wild-type mouse. Negative sweeps indicate the voltage deflections evoked by a constant current pulse of $-0.3 \mathrm{nA}$ (150 msec duration), indicating that the membrane resistance is reduced during 5HT application. $B, C$, The change in membrane potential $(B)$ and resistance $(C)$ evoked by $5 \mathrm{HT}$ is increased in heterozygous animals $(+/-$, $n=9$ animals), when compared to the wild-type controls $(+/+, n=7)$ or homozygous GR knockout animals $(-/-, n=8)$.
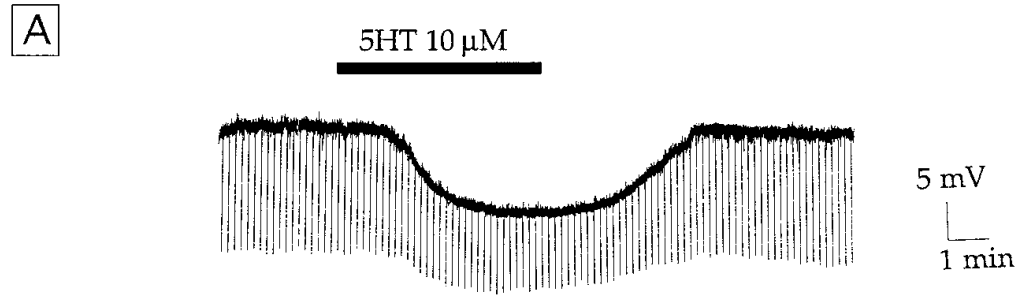

B

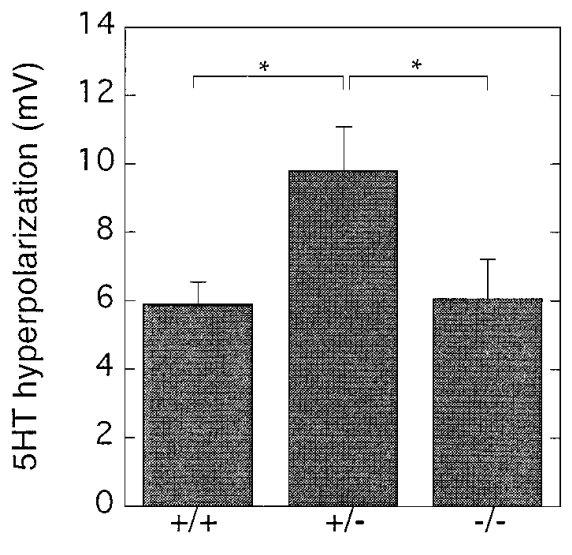

C

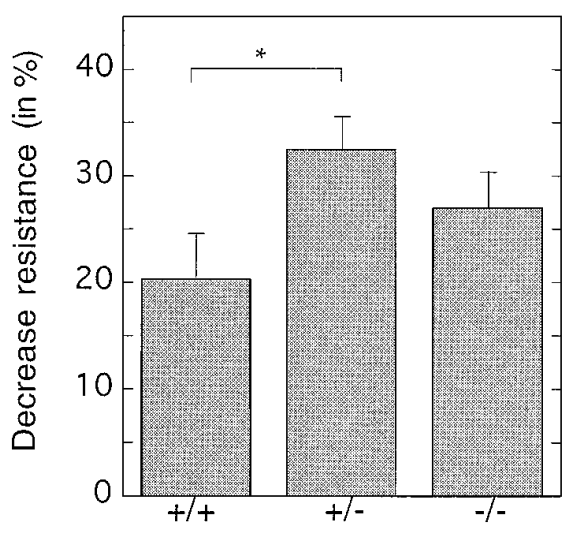




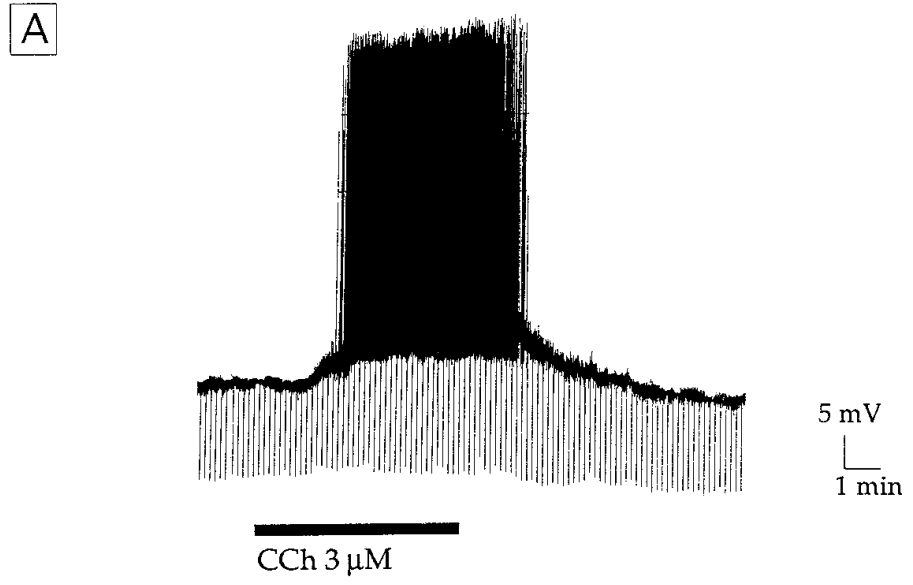

B

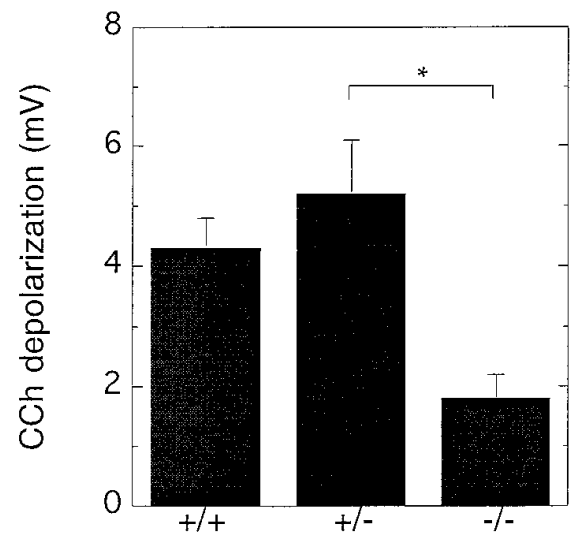

C

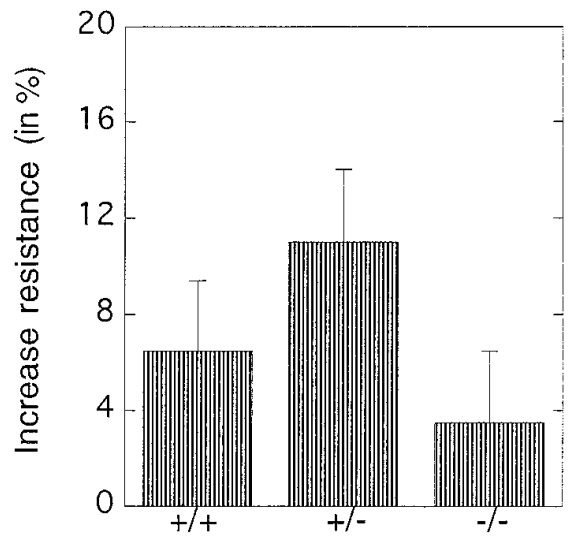

Figure 4. $A$, Depolarization of the membrane evoked by $3 \mu \mathrm{M}$ of the metabolically stable cholinergic analog carbachol $(C C h)$. In this example the neuron reaches the firing threshold during the CCh application. Spikes are truncated. $B, C$, Mean $(+\mathrm{SEM})$ change in membrane potential $(B)$ and resistance $(C)$ for the three experimental groups. In the heterozygous GR knockout group, membrane depolarization induced by CCh was significantly enhanced compared to the homozygous knockouts. erozygous and wild-type mice $(-4.1 \pm 0.7$ and $-6.2 \pm 0.5 \mathrm{mV} ; n=$ 5 and 4 animals, respectively) was not significantly different from the values in the intact wild-type $(-5.9 \pm 0.5 \mathrm{mV})$ or homozygous mutants $(-6.0 \pm 0.9 \mathrm{mV})$.

In contrast to $5 \mathrm{HT}$, CCh depolarized the membrane of CA1 hippocampal neurons in wild-type controls (Fig. 4A). The experiments were performed with $3 \mu \mathrm{M} \mathrm{CCh}$, a dose that was found to induce half-maximal responses (Hesen and Joëls, 1993). With 3 $\mu \mathrm{M}$ CCh, the average depolarization was limited $(4.3 \pm 0.5 \mathrm{mV}$ for the wild-type group), but still could result in onset of spontaneous firing (Fig. 4A). Depolarizing $\mathrm{CCh}$ responses recorded in neurons from heterozygous animals were increased when compared with the wild-type control group and the homozygous mutants $(p<$ 0.05; Fig. 4B). After adrenalectomy, CCh responses of heterozygous animals $(3.8 \pm 0.6 \mathrm{mV})$ were significantly reduced to the level of the intact wild-type controls or homozygous mutants. Responses in wild types were not affected by adrenalectomy $(4.1 \pm 1.6 \mathrm{mV})$.

\section{Hexokinase activity}

To get an impression of the metabolic activity in the CA1 hippocampal region in the three groups of animals, we determined the activity of hexokinase, the first rate-limiting enzyme in glucose metabolism, by quantitative enzyme histochemistry (van Raamsdonk et al., 1996). Hexokinase activity was determined in the pyramidal cell body layer, in the dendritic layers in stratum oriens and stratum lacunosum/moleculare, and as a control in the fim- bria. No significant differences were observed for hexokinase activity in the fimbria, the pyramidal cell body layer, and the stratum lacunosum/moleculare (Table 2). In the stratum oriens, however, hexokinase activity was highest in the heterozygous group and lowest in the homozygous animals, whereas the wildtype group was at an intermediate level.

\section{DISCUSSION}

The aim of this study was to examine the corticosteroid-mediated control of hippocampal cell properties under conditions in which functional GRs are fully absent. To this purpose we used mice

Table 2. Hexokinase acticity as determined by quantitative enzyme histochemistry

\begin{tabular}{lccll} 
& $N$ & Wild type & Heterozygous & Homozygous \\
\hline Fimbria & 7 & $48.6 \pm 1.4$ & $47.1 \pm 1.6$ & $45.6 \pm 2.8$ \\
S. mol/lac & 7 & $34.4 \pm 2.2$ & $36.1 \pm 1.7$ & $31.6 \pm 2.1$ \\
S. pyramidale & 7 & $21.3 \pm 2.0$ & $25.3 \pm 1.5$ & $21.3 \pm 2.0$ \\
S. oriens & 7 & $35.3 \pm 0.7$ & $37.0 \pm 1.2^{*}$ & $31.3 \pm 2.6$
\end{tabular}

The data represent mean integrated absorbance in the indicated hippocampal CA1 subfields. Heterozygous animals showed on average high values for hexokinase activity in stratum moleculare/lacunosum (S. mol/lac), stratum pyramidale (S. pyramidale), and stratum oriens (S. oriens). Only in the latter area did this difference attain statistical significance against the value in the homozygous mutants. Control observations in the fimbria did not exhibit increased activity of the heterozygous group. 
Figure 5. Relative Ca current amplitude (circles) and responses to 5HT (squares) or CCh (triangles), expressed as a percentage of the maximal response observed in tissue from rats. Data from earlier studies in rats (open symbols) indicate that these parameters exhibit a U-shaped dose-dependency on steroid receptor occupation (based on Joëls and de Kloet, 1992; Hesen and Joëls, 1993, 1996a,b; Karst et al., 1994). Large Ca currents and transmitter responses were seen either when no receptors were occupied (in tissue from ADX rats, I) or when MRs and GRs were considerably activated, i.e., in tissue from mildly stressed adrenally intact rats $(I I I)$ or adrenally intact rats receiving a high corticosterone dose $(I V)$. Small responses were seen with a predominant MR activation $(I I)$. Relative MR and GR occupation for the rat studies is indicated below. Ca current amplitude and transmitter responses in mildly stressed, adrenally intact wild-type mice $(+/+$, filled symbols, $I I I)$ were very similar to the responses obtained in rats; differences amounted to $<5 \%$. The responses in mice homozygous for a GR gene mutation $(-/-)$, which display an exclusive MR activation, did not resemble the data obtained previously in rats with predominant MR activation (II). Instead, the responses in mice more closely resemble the responses in $\mathrm{ADX}$ rats $(I)$ and mice (Fig. 2). This may point to the necessity of functional GRs to accomplish MR-mediated events. Responses obtained in mice heterozygous for the mutation $(+/-)$ were large, most closely resembling the responses found previously in rats in which almost all of the available GRs were activated, in addition to MRs (IV). Explanations for these findings are discussed in the text.

with a genetic defect in the GR, obtained by homologous recombination techniques. Recently, several properties of peripheral tissues have been described for these animals (Cole et al., 1995). It appeared that because of the impaired negative feedback, plasma corticosterone levels in heterozygous and homozygous animals directly after birth were increased twofold and almost threefold, respectively. The plasma corticosterone levels presently observed in the three groups of adult mice agree with these earlier findings. In all presently tested groups, plasma corticosterone levels were slightly raised, most likely because of the fact that all mice were exposed to a novel environment during a 30-60 min period preceding the start of the experiment. The raised plasma corticosterone levels, however, may also reflect differences in basal activity of the hypothalamic-pituitary-adrenal system, particularly in the heterozygous and homozygous mutant mice.

The MR and GR mRNA expression levels observed in the hippocampi of the animals included in the present study agree with a defect in the GR feedback function. Thus, in the homozygous animals, GR expression was undetectable. In heterozygous animals, GR (but not MR) mRNA expression in the CA1 hippocampal area was reduced compared with that in the wild-type controls. If the change in mRNA expression is translated to an altered protein level, this points to a reduced amount of GRs. This observation strengthens the idea that not only the homozygous but also the heterozygous animals are disturbed with respect to their neuroendocrine regulation.

In a previous report it was shown that GR-deficient mice differed in the function of at least two organ systems. First, it was observed that the adrenal medulla was impaired in function in the heterozygous animals and was almost absent in the homozygous animals (Cole et al., 1995). Accordingly, noradrenaline levels were reduced in the homozygous (but not heterozygous) mice, whereas adrenaline was diminished in the heterozygous group and not detectable in the homozygous group. This deficiency, and possibly others, which co-inherit with the GR gene disruption, may have indirect consequences for the development and function of brain circuits (Gerlai, 1996). This also pertains to the second observation, i.e., that homozygous GR knockout mice have a very high mortality rate in the first hours after birth, probably attributable to imperfect lung maturation (Cole et al., 1995). In a previous study it was found that only $5-10 \%$ of the homozygous offspring survive this critical period immediately after birth. The mortality rate during the rest of their lifespan is not different from that of the heterozygous or wild-type animals. Possibly, properties other than the GR expression, which can vary widely in a population, add to the higher chances of survival in these $5-10 \%$ of the animals. This may inadvertently have biased the group of homozygous mutants and the properties that we recorded. Clearly, these considerations stress that the presently obtained results, particularly with the homozygous GR knockouts, should be interpreted cautiously. Still, these animals represent the only presently available animal model in which MR function can be studied in the total absence of GRs.

In the wild-type mice, passive membrane properties were comparable to those observed previously in adrenally intact rats (Joëls et al., 1991; Hesen and Joëls, 1993), although the input resistance of the cells was somewhat higher, indicating a smaller cell size. Properties of the Ca currents in wild-type mice were also comparable to what was reported in rats, with respect to both voltage dependency and kinetics (Fig. 5) (Karst et al., 1994; Joëls and Karst, 1995). Similarly, the dose-response range and changes in membrane properties observed with application of $5 \mathrm{HT}$ or $\mathrm{CCh}$ 
did not differ markedly from responses in rats (Andrade and Nicoll, 1987; Dutar and Nicoll, 1988; Joëls et al., 1991; Hesen and Joëls, 1993). This allows a careful comparison with data obtained previously in studies with rats.

In earlier studies in rats, we observed that predominant MR occupation is associated with small Ca current amplitudes and small responses to 5HT and CCh (Fig. 5) (Joëls et al., 1991; Hesen and Joëls, 1993; Karst et al., 1994). If these effects are caused exclusively by MR activation, one would expect to see similar responses in the homozygous mutant mice; however, we observed that in particular the $\mathrm{Ca}$ currents and 5HT responses were rather large in cells from the homozygous mutants; basic membrane properties were unaffected. The presently observed combination of large $\mathrm{Ca}$ current amplitudes and 5HT responses and rather small $\mathrm{CCh}$ responses in cells from homozygous mutant mice most closely resembles the cellular features observed previously in tissue from ADX rats (cf. Fig. 5) (Joëls and de Kloet, 1989; Hesen and Joëls, 1993, 1996a,b; Kerr et al., 1992). Accordingly, ADX wild-type or ADX heterozygous mice displayed responses comparable to those observed in the homozygous mice, but different from either the adrenally intact wild-type (Ca currents) or heterozygous (transmitter responses) groups. We tentatively conclude that exclusive activation of MRs does not greatly alter cellular responses of CA1 neurons when compared with the situation in which no steroid receptors are activated. This may indicate that some degree of MR/GR heterodimerization or synergism in MR/ GR-mediated action is required, as was found previously in transfected cell systems (Arriza et al., 1988; Trapp et al., 1994).

Heterozygous GR mutants displayed large Ca current amplitudes, when compared with the wild-type control group, and significantly increased responses to 5HT and CCh. This combination of responses most closely, although not entirely, resembles the combination of cellular effects observed previously in rats subjected to very high corticosteroid levels, thus extensively activating GRs in addition to MRs (cf. Fig. 5) (Kerr et al., 1992; Hesen and Joëls, 1996a,b). Plasma corticosterone levels of the presently tested heterozygous animals, although clearly increased compared with those of the wild-type controls, were not extremely high. The moderately elevated plasma corticosterone levels, however, were combined to a significantly reduced GR mRNA level in the CA1 area. This may signify that similar to the situation studied previously in rats, an extensive activation of the available GRs took place in these animals. Clearly, further study of the binding properties of GRs in the heterozygous animals is necessary to substantiate this assumption. Also, a complete corticosteroid dose-dependency of the examined parameters needs to be established in mice. Meanwhile, several alternative explanations should be considered. One possibility is that the U-shaped dosedependency observed in earlier studies based on findings with acute changes in plasma steroid level does not hold when the neuroendocrine state of the animal is chronically altered, as is the case for the heterozygous mice. This is supported by recent data showing that chronically elevated corticosteroid levels affect 5HT responses in CA1 neurons differently than acute rises in plasma corticosterone level (Beck et al., 1996). Alternatively, large Ca currents and transmitter responses in the heterozygous group could be explained by adaptive changes in brain circuitry, arising during early development, of heterozygous GR mutant mice.

Interestingly, previous studies in tissue from rats indicated that glucose metabolism in hippocampal cells is inversely related to the degree of GR activation (Kadekaro et al., 1988; Horner et al., 1990). We observed in this study that the activity of hexokinase, a rate-limiting enzyme in the cellular glucose metabolism, did not show such a linear dependency on available GRs. Thus, hexokinase activity was quite large in the heterozygous mice compared with the homozygous and wild-type control groups. It will be interesting to test whether other cell properties indicative for metabolism, e.g., the activity of the glucose transporter, are similarly or differently regulated in the present animal model.

In conclusion, the present findings indicate that cellular properties in hippocampal neurons in which GRs are fully absent resemble the properties observed when both MRs and GRs are lacking. This may point to the necessity of functional GRs for the development of MR-mediated effects. Furthermore, the data indicate that a reduction of the available GRs may alter the dosedependency for steroid actions on excitability. Cellular properties recorded in animals with moderately elevated plasma corticosterone levels and reduced GR mRNA expression closely resembled the situation seen previously in rats with very high corticosteroid levels. These two observations illustrate the use of animals with genetically modified GR expression for the study of hormone actions in the brain (Barden et al., 1995). The interpretation of the present data, however, is hampered by the fact that particularly homozygous GR knockout animals lack both peripheral and central GR activation, from early development onward. Therefore, future studies in site-specific, inducible knockout animals will be required to elaborate the present findings.

\section{REFERENCES}

Andrade R, Nicoll RA (1987) Pharmacologically distinct actions of serotonin on single pyramidal neurones of the rat hippocampus recorded in vitro. J Physiol (Lond) 394:99-124.

Arriza JL, Weinberger C, Cerelli G, Glaser TM, Handelin BL, Housmann DE, Evans RM (1987) Cloning of human mineralocorticoid receptor cDNA: structural and functional kinship with the glucocorticoid receptor. Science 237:268-275.

Arriza JL, Simerly RB, Swanson LW, Evans RM (1988) The neuronal mineralocorticoid receptor as a mediator of glucocorticoid response. Neuron 1:887-900.

Barden N, Reul JMHM, Holsboer F (1995) Do antidepressants stabilize mood through actions on the hypothalamic-pituitary-adrenocortical system? Trends Neurosci 18:6-11.

Beck SG, Choi KC, List TJ, Okuhara DY, Birnstiel S (1996) Corticosterone alters 5-HT1A receptor mediated hyperpolarization in area CA1 hippocampal pyramidal neurons. Neuropsychopharmacology 14:27-33.

Chao HM, Choo PH, McEwen BS (1989) Glucocorticoid and mineralocorticoid receptor mRNA expression in rat brain. Neuroendocrinology 50:365-372.

Cole TJ, Blendy JA, Monaghan AP, Krieglstein K, Schmid W, Aguzzi A, Fantuzzi G, Hummler E, Unsicker K, Schütz G (1995) Targeted disruption of the glucocorticoid receptor gene blocks adrenergic chromaffin cell development and severely retards lung maturation. Genes Dev 9:1608-1621.

de Kloet ER (1991) Brain corticosteroid receptor balance and homeostatic control. Front Neuroendocrinol 12:95-164.

Dutar P, Nicoll RA (1988) Classification of muscarinic responses in hippocampus in terms of receptor subtypes and second messenger systems: electrophysiological studies in vitro. J Neurosci 8:4214-4224.

Edwards FA, Konnerth A, Sakmann B, Takahashi T (1989) A thin slice preparation for patch clamp recordings from neurones of the mammalian central nervous system. Pflügers Arch 414:600-612.

Fuxe K, Wikstrom AC, Okret S, Agnati LF, Harfstrand A, Yu Z-Y, Granholm L, Zoli M, Vale W, Gustafsson JA (1985) Mapping of glucocorticoid receptor immunoreactive neurons in the rat tel- and diencephalon using a monoclonal antibody against rat liver glucocorticoid receptors. Steroid Biochem 23:247-251.

Gagne D, Pons M, Philibert D (1985) RU 38486: a potent antiglucocorticoid in vitro and in vivo. J Steroid Biochem 23:247-251.

Gerlai R (1996) Gene-targeting studies of mammalian behavior: is it the mutation or the background genotype? Trends Neurosci 19:177-180.

Herman JP, Patel PD, Akil H, Watson SJ (1989) Localization and regulation of glucocorticoid and mineralocorticoid receptor messenger 
RNAs in the hippocampal formation of the rat. Mol Endocrinol 3:1886-1894.

Hesen W, Joëls M (1993) Modulation of carbachol responsiveness in rat CA1 pyramidal neurons by corticosteroid hormones. Brain Res 627:159-167.

Hesen W, Joëls M (1996a) Modulation of 5HT1A responsiveness in CA1 pyramidal neurons by in vivo activation of corticosteroid receptors. J Neuroendocrinol 8:433-438.

Hesen W, Joëls M (1996b) Cholinergic responsiveness of rat CA1 hippocampal neurons in vitro: modulation by corticosterone and stress. Stress, 1:65-72.

Hollenberg SM, Weinberger C, Ong ES, Cerelli G, Oro A, Lebo R, Thompson EB, Rosenfeld MG, Evans RM (1985) Primary structure and expression of a functional human glucocorticoid receptor cDNA. Nature 318:635-641.

Horner H, Packan D, Sapolsky R (1990) Glucocorticoids inhibit glucose transport in cultured hippocampal neurons and glia. Neuroendocrinology 52:57-64.

Joëls M, de Kloet ER (1989) Effects of glucocorticoids and norepinephrine on the excitability in the hippocampus. Science 245:1502-1505.

Joëls M, de Kloet ER (1992) Coordinative mineralocorticoid and glucocorticoid receptor-mediated control of responses to serotonin in rat hippocampus. Neuroendocrinology 55:344-350.

Joëls M, de Kloet ER (1993) Corticosteroid actions on amino acidmediated transmission in rat CA1 hippocampal cells. J Neurosci 13:4082-4090.

Joëls M, de Kloet ER (1994) Mineralocorticoid and glucocorticoid receptors in the brain: implications for ion permeability and transmitter systems. Prog Neurobiol 43:1-36.

Joëls M, Karst H (1995) Effects of estradiol and progesterone on voltagegated calcium and potassium conductances in rat CA1 hippocampal neurons. J Neurosci 15:4289-4297.

Joëls M, Hesen W, de Kloet ER (1991) Mineralocorticoid hormones suppress serotonin-induced hyperpolarization of rat hippocampal CA1 neurons. J Neurosci 11:2288-2294.

Kadekaro M, Masanori I, Gross P (1988) Local cerebral glucose utilization is increased in acutely adrenalectomized rats. Neuroendocrinology 47:329-334.

Karst H, Joëls M, Wadman WJ (1993) Low-threshold calcium current in dendrites of adult rat hippocampus. Neurosci Lett 164:154-158.

Karst H, Wadman WJ, Joels M (1994) Corticosteroid receptordependent modulation of calcium currents in rat hippocampal CA1 neurons. Brain Res 649:234-242.
Kay AR, Miles R, Wong RKS (1986) Intracellular fluoride alters the kinetic properties of calcium currents facilitating the investigation of synaptic events in hippocampal neurons. J Neurosci 6:2915-2929.

Kerr DS, Campbell LW, Thibault O, Landfield PW (1992) Hippocampal glucocorticoid receptor activation enhances voltage-dependent Ca conductances: relevance to brain aging. Proc Natl Acad Sci USA 89:8527-8531.

McEwen BS, Weiss JM, Schwartz L (1968) Selective retention of corticosterone by limbic structures in rat brain. Nature 220:911-912.

McEwen BS, de Kloet ER, Rostene W (1986) Adrenal steroid receptors and actions in the nervous system. Physiol Rev 66:1121-1188.

Ratka A, Sutanto W, Bloemers M, de Kloet ER (1989) On the role of brain mineralocorticoid (Type I) and glucocorticoid (Type II) receptors in neuroendocrine regulation. Neuroendocrinology 50:117-123.

Reul JMHM, de Kloet ER (1985) Two receptor systems for corticosterone in rat brain: microdissection and differential occupation. Endocrinology 117:2505-2512.

Reul JMHM, Van den Bosch JR, de Kloet ER (1987a) Differential response of type 1 and type 2 corticosteroid receptors to changes in plasma steroid levels and circadian rhythmicity. Neuroendocrinology 45:407-412.

Reul JMHM, Van den Bosch JR, de Kloet ER (1987b) Relative occupation of type 1 and type 2 corticosteroid receptors in rat brain following stress and dexamethasone treatment: functional implications. J Endocrinol 115:459-467.

Trapp T, Holsboer F (1996) Heterodimerization between mineralocorticoid and glucocorticoid receptors increases the functional diversity of corticosteroid action. Trends Pharm Sci 17:145-149.

Trapp T, Rupprecht R, Castren M, Reul JMHM, Holsboer F (1994) Heterodimerization between mineralocorticoid and glucocorticoid receptor: a new principle of glucocorticoid action in the CNS. Neuron 13:1457-1462.

Van Eekelen JAM, Kiss JZ, Westphal HM, de Kloet ER (1987) Immunocytochemical study on the intracellular localization of the Type 2 glucocorticoid receptor in the rat brain. Brain Res 436:120-128.

Van Eekelen JAM, Jiang W, de Kloet ER, Bohn MC (1988) Distribution of the mineralocorticoid and glucocorticoid receptor mRNAs in the rat hippocampus. J Neurosci Res 21:88-94.

Van Raamsdonk W, Smit-Onel MJ, Diegenbach PC (1996) Quantitative enzyme- and immunohistochemistry of hexokinase and cytochrome c oxidase of spinal neurons in the zebrafish. Acta Histochem 98:143-155. 